\title{
RESPONSABILIDAD MÉDICA EN LA EMERGENCIA SANITARIA $^{1}$
}

\author{
MEDICAL LIABILITY IN \\ HEALTH EMERGENCY
}

DRA. NATALIA VELOSO GIRIBALDI*

Resumen: El presente trabajo tiene como objetivo analizar el impacto de la emergencia sanitaria decretada a raíz de la expansión del COVID-19 en la responsabilidad médica.

Palabras Clave: responsabilidad médica, emergencia sanitaria, Covid-19

Summary: The purpose of this work is to analyze how medical liability is impacted by the health emergency declared as a result of the expansion of COVID-19.

Key words: Medical Liability, health emergency, Covid-19

\section{NOCIONES GENERALES SOBRE RESPONSABILIDAD MÉDICA}

\subsection{Concepto general de responsabilidad médica}

La responsabilidad médica no es otra cosa más que la imputación de las consecuencias jurídicas que el ordenamiento jurídico le impone a los galenos por su actuar culpable en el ejercicio de su profesión.

Muchas veces, la responsabilidad médica es confundida o identificada con la responsabilidad civil médica. Sin embargo, la responsabilidad médica es mucho más amplia, ya que además de responsabilidad civil, el médico enfrenta consecuencias por su actuación en el ámbito penal, en el ámbito administrativo e inclusive en el plano ético.

Por tales razones, a continuación, se procederá a categorizar los distintos ámbitos en que puede verse comprometida la responsabilidad médica y las diferentes implicancias jurídicas que las mismas conllevan.

\footnotetext{
Doctora en Derecho por la Universidad de Montevideo (2005), Máster en Derecho Administrativo Económico (2011), Diploma en Derecho de la Salud por la Universidad Austral de Buenos Aires (cursando), Profesor Agregado de Derecho Administrativo en la Universidad de Montevideo (2006-2019), Profesora de Derecho Público en el Posgrado de Gestión Financiera en Instituciones Públicas de la Facultad de Ciencias Económicas de la Universidad de la República (2017-2020), autora de varios libros y trabajos publicados en el país y en el extranjero. ORCID ID: 0000-0002-5340-2906. natalia.veloso@delpiazzo.com

1 Conferencia brindada el 8 de junio de 2020 vía webinar para la Universidad de Montevideo.
} 


\subsection{Responsabilidad Penal}

La responsabilidad médica en el ámbito penal se verifica cuando se configuran los delitos de omisión de asistencia o los delitos de homicidio o de lesiones previstos por la legislación penal.

La omisión de asistencia se produce cuando por negligencia, se deja de prestar asistencia a un individuo cuya vida o integridad física corren peligro (art. 332 del Código Penal).

Por su parte, los delitos de homicidio o lesiones se producen cuando el galeno causa la muerte o lesiona al paciente como consecuencia de su obrar médico culpable (art. 310 y ss. y 316 y ss. del Código Penal). En efecto, nuestra más prestigiosa Doctrina ha señalado que la mala praxis que apareja responsabilidad penal es aquella en que: "el facultativo produce, con su conducta terapéutica o asistencial, un resultado que no previó, que no anticipó y que, sin embargo, era anticipable, representable y objetivamente previsible" ${ }^{2}$.

En estos casos, la responsabilidad penal se materializa a través de una sentencia de condena, recaída al cabo de un proceso judicial, en la cual se condena al médico a una pena que puede ser de prisión o de penitenciaría.

\subsection{Responsabilidad Civil}

La responsabilidad médica en el ámbito civil, o responsabilidad civil médica, es aquella que se produce cuando el médico con su actuar médico culpable, genera un daño al paciente susceptible ser indemnizado ${ }^{3}$.

En efecto, en el ámbito civil se reclama la reparación o indemnización de los daños y perjuicios producidos a causa del actuar médico, los cuales incluyen el daño moral padecido por la víctima o sus deudos, el daño material y el lucro cesante.

Dicho reclamo se procesa ante la justicia civil, en un juicio ordinario en el que, para probar la responsabilidad, tal como se desarrollará más adelante, se deberá probar la existencia de culpa médica, el daño y el nexo de causalidad entre la actuación médica culposa y dicho daño (1342 C.C.).

\subsection{Responsabilidad Administrativa}

La responsabilidad administrativa o también llamada disciplinaria es la que se configura cuando el médico comete una infracción administrativa en ejercicio de su función pública en una institución de asistencia médica del Estado.

2 Gonzalo FERNÁNDEZ - “El ejercicio ilegal de la medicina: Las hipótesis de responsabilidad penal”, en III Jornadas de Responsabilidad Médica (1998)", S.M.U., pág. 54.

3 Ver: Alfredo ACHÁVAL - "Responsabilidad Civil del Médico", Buenos Aires, 1992, Abeledo Perrot, Segunda Edición Ampliada y Actualizada, pág. 129 y ss. 
En efecto, de acuerdo a lo dispuesto por el art. 169 del Decreto $N^{\circ} 500 / 991$, de 27 de setiembre de 1991, “La falta susceptible de sanción disciplinaria, es todo acto u omisión del funcionario, intencional o culposo, que viole los deberes funcionales".

Quiere decir que la norma exige para que se configure una falta la existencia de dos elementos: a) un elemento objetivo consistente en la violación de deberes funcionales; y b) un elemento subjetivo pautado por la presencia de intencionalidad o culpa.

En cuanto al elemento objetivo, entre los deberes funcionales del médico se encuentra el de actuar acorde a la lex artis, por lo que probado dicho apartamiento queda probado también el elemento objetivo de la infracción administrativa.

En cuanto al elemento subjetivo, para que se configure infracción administrativa deberá demostrarse la existencia de un actuar culposo, esto es, haber actuado con impericia, imprudencia o negligencia. Si dicho comportamiento no queda probado, entonces no habrá infracción administrativa y por tanto responsabilidad disciplinaria ${ }^{4}$.

Dicho procedimiento disciplinario se sustancia a través de un sumario administrativo, que es el procedimiento tendiente a determinar o comprobar la responsabilidad de los funcionarios imputados de la comisión de falta administrativa y a su esclarecimiento (art. 182 del Decreto 500/91).

Al cabo de dicho sumario puede recaer una sanción administrativa que puede ir, desde una observación sin anotación en el legajo, a una suspensión en el ejercicio de sus funciones por un máximo de seis meses o inclusive, hasta la destitución del funcionario.

Por último, en el ámbito administrativo tampoco puede desconocerse la función que cumple la Comisión de Salud Pública del Ministerio de Salud Pública creada por la Ley $\mathrm{N}^{0} 9.202$ de 12 de enero de 1934. En efecto, dicha Comisión tiene entre sus cometidos el de constituirse en "tribunal disciplinario, juzgar y reprimir las faltas cometidas por los médicos y los que ejercen profesiones anexas en el ejercicio de su profesión, cuando éstos se aparten del cumplimiento de las normas generales que determinen las Ordenanzas y Reglamentos" (art. 26 y ss.).

En ejercicio de dichas potestades, la Comisión de Salud Pública dictamina en vía administrativa sobre la responsabilidad del médico en su actuación funcional, pudiendo imponerle sanciones que van desde una mera observación hasta la suspensión de la habilitación para ejercer la medicina, la cual puede tener una duración máxima de 10 años 5 .

4 En este sentido, corresponde enfatizar con nuestra doctrina más prestigiosa que, en el orden disciplinario, no se admiten las infracciones objetivas. Ver: Mariano R. BRITO - "Régimen disciplinario. Principios fundamentales del procedimiento, infracción y sanción disciplinarios", en Procedimiento administrativo, Acali. Montevideo, 1977, pág. 138; Augusto DURAN MARTINEZ - "Principios del procedimiento disciplinario", en Procedimiento administrativo, UCUDAL, Montevideo, 1991, pág. 82 y Susana LORENZO - "Sanciones administrativas", BDF, Montevideo, 1996, pág. 142.

5 Miguel A TOMA,- “Comisión de Salud Pública. Ley 9.202". Revista de la Oficina Nacional del Servicio Civil. Año I-2006. No 30. Pág. 156 
Dichas sanciones constituyen actos administrativos y son, por tanto, recurribles mediante recursos administrativos y procesables por el afectado ante el Tribunal de lo Contencioso Administrativo, una vez agotada la vía administrativa.

\subsection{Responsabilidad Ética}

La Ley N 18.591 de 16 de octubre de 2009, creó el Colegio Médico del Uruguay como persona pública no estatal con el cometido de garantizar al médico y a la comunidad, el ejercicio de la profesión dentro del marco deontológico establecido.

La colegiación en dicha institución es obligatoria para el ejercicio de la medicina, por lo que todos los médicos que ejerzan la profesión deberán estar inscriptos en el Colegio Médico y quedarán por tanto sometidos a su regulación y a lo que disponga el Tribunal de Ética Médica del Colegio Médico.

Dicho Tribunal, es competente para entender en todos los casos de ética, deontología y diceología médicas que le sean requeridos por el Estado, personas físicas o jurídicas o por integrantes del Colegio Médico del Uruguay. Es decir, que el Tribunal tiene competencia para entender no solo en las denuncias que formulen los médicos contra otros médicos, sino en las denuncias que formule cualquier persona física o jurídica.

Una vez formulada la denuncia, el Tribunal de Ética Médica llevará adelante un procedimiento normado por la ley, al cabo del cual podrá imponer las siguientes sanciones, en orden de gravedad: a) advertencia; b) amonestación; c) sanción educativa: entendiendo por tal la realización de cursos de desarrollo profesional médico continuo y d) suspensión temporal del Registro por un plazo máximo de diez años (art. 28).

En este sentido, adviértase que la suspensión temporal del registro del Colegio Médico equivale a la suspensión de la habilitación para ejercer la medicina, ya que para poder ejercer la medicina es necesario estar inscripto en el Colegio Médico, y esta sanción justamente lo que hace es suspender dicha inscripción.

Por otra parte, debe tenerse en cuenta que, para aprobar la suspensión del Registro de un miembro del Colegio, se requerirá una mayoría especial de votos, correspondiente a cuatro de los cinco miembros del Tribunal de Ética Médica (art. 29).

Dichas sanciones, no son actos administrativos en tanto emanan de una persona pública no estatal, por lo que no son recurribles mediante recursos administrativos ni tampoco procesables ante el TCA, por lo que habrá que estar al régimen impugnativo especial dispuesto por el art. 30 de la Ley $\mathrm{N}^{\mathrm{o}} 18.591$.

En definitiva, la responsabilidad médica es mucho más amplia que la responsabilidad médica civil ya que puede configurarse tanto en el ámbito penal, como en el ámbito civil, administrativo o ético, siendo distintas las consecuencias jurídicas que se imputan dependiendo del ámbito de actuación. No obstante, siendo la responsabilidad médica civil la que más desarrollos doctrinarios y jurisprudenciales ofrece, es necesario ahondar en su caracterización a los efectos de conocer los alcances de dicho instituto jurídico. 


\section{ESPECIFICIDADES DE LA RESPONSABILIDAD CIVIL MÉDICA}

\subsection{La obligación de medios.}

La responsabilidad civil médica se enmarca dentro de lo que es la responsabilidad civil general, y en especial, la responsabilidad subjetiva, en la cual se establece que el médico no se obliga a sanar al enfermo sino a dedicarle la atención cuidadosa, prudente y técnica, que corresponde al grado de evolución de la ciencia. El médico está obligado a realizar una actividad diligente en el ejercicio de su profesión, y si lo hace, no podrá ser responsabilizado, aunque la operación fracase y aunque el enfermo no se cure, se agrave o muera ${ }^{6}$.

En nuestro país "El galeno no responde por el riesgo creado, sino sólo en la medida en que su actuar infrinja el canon de la diligencia del profesional médico [...]. La obligación de la prestación de asistencia médica no es una obligación de resultado sino de medios, lo que influye en la carga de la prueba. La mutualista o el médico sólo responderá si el paciente, socio, y por ende parte en el contrato, prueba que fue mal asistido, con torpeza científica o con desatención o con negligencia" ${ }^{7}$.

En efecto, como acertadamente sostiene Gamarra, la ausencia de responsabilidad en estos casos deriva del principio general de la responsabilidad médica, por el cual no hay responsabilidad sin culpa o a las reglas que regulan la relación causal (eximentes de responsabilidad o causa extraña no imputable) $)^{8}$.

\subsection{El apartamiento de la lex artis. La culpa médica.}

Para que incumpla se requiere la culpa; ésta es el reverso negativo del obrar diligente, puesto que el art. 1344 del Código Civil la define como la "falta del debido cuidado o diligencia"

En puridad, la culpa médica, es un modo de denominar a la culpa civil, la que se verifica cuando el galeno se aparta del modelo o standard que impone el arte médico. La culpa se define como un acto médico ejercido contra la regla técnica y violatorio del standard consagrado por las reglas y prácticas de la Medicina. La culpa implica una violación de la ley del arte, de la llamada lex artis ad hoc.

Asimismo, en cuanto al error de diagnóstico se ha dicho concretamente que: "no todo error de diagnóstico equivale a culpa. $\mathrm{O}$ sea que algunos errores hacen incurrir al médico en responsabilidad, mientras que otros no son suficientes para condenarlo". El error que hace incurrir en responsabilidad al médico es el error inexcusable. Esto

6 Así: Jorge GAMARRA -“Responsabilidad Civil Médica”, FCU, Montevideo, 1999, Tomo I, págs. 16.

7 Sentencia No 729/96, de 22/07/94, SCJ, LJU, caso 13.188; ver también Sentencia N 45/2003, del 20/032/2003, TAC $6^{\circ}$ Turno, LJU, tomo 128, suma 128022; Dora SZAFIR y Beatriz Venturini, "Responsabilidad médica en el MERCOSUR. Jurisprudencia sistematizada y anotada. Cuadernos del ADCU, tomo II, págs. 387 a 394.

8 Así: Jorge GAMARRA -“Responsabilidad Civil Médica, cit, Tomo I, págs. 16.

9 Así: Jorge GAMARRA -“Responsabilidad Civil Médica”, cit., Tomo I, págs. 9 y 10; ver también Ricardo RAVINOVICH “Responsabilidad del Médico", Astrea, Buenos Aires, 1999, p.107 y 108. 
es, aquel que deriva de un diagnóstico que no se habría emitido si el médico hubiera actuado con diligencia ${ }^{10}$.

A modo de ejemplo, se entiende que "es excusable el error cuando no se verifica sintomatología o los síntomas presentan variantes"11. Asimismo, se entiende también que el error de diagnóstico es excusable cuando el paciente presentaba síntomas comunes a varias enfermedades ${ }^{12}$ y cuando existen discusiones científicas sobre el tema ${ }^{13}$.

Por el contrario, se entiende que sí existe error de diagnóstico inexcusable cuando "se rotuló al paciente con determinado diagnóstico sin practicarse los estudios para confirmarlo o descartarlo cuando existían signos que autorizaban a dudar del mismo, optándose por acudir a una tomografía, de resultados inciertos y descartando una mielografía, indispensable para asegurarlo"14.

La consecuencia de que el error de diagnóstico sea excusable es que el mismo no genera responsabilidad médica. Es decir, el médico no responde por el error excusable sino únicamente por aquel que se considera inexcusable.

Por último, para su apreciación también se ha señalado que no puede juzgarse al profesional "con el diario del lunes", sino que, por el contrario, quien juzga el proceder médico debe ponerse en la misma situación en que estaba el médico al momento de efectuar el diagnóstico o al momento de tomar la decisión terapéutica. En este sentido, se ha señalado que: "El tribunal debe colocarse ante y no ex post facto" "quien pretende formarse un juicio debe colocarse en el día y la hora en que el profesional debió tomar una decisión"15.

\subsection{El nexo causal}

Para que exista responsabilidad médica, no basta con analizar si existió o no culpa del médico actuante. Además de ello, es necesario que ese comportamiento culposo sea el causante del daño sufrido por el paciente. Asimismo, tampoco alcanza con el comportamiento culpable por sí solo para responsabilizar al prestador del servicio asistencial; sino que debe existir una conexión o relación de causalidad entre ese comportamiento culpable y el daño ${ }^{16}$. Como consecuencia de ello, el damnificado va a tener que probar dicha relación de causalidad ${ }^{17}$.

Este extremo, es de fundamental importancia ya que no basta con un actuar culpable del médico, sino que debe probarse además que fue dicho actuar culposo el que generó el daño. Si el daño se hubiese producido de cualquier forma con independencia del actuar médico, entonces no podrá configurarse la responsabilidad médica.

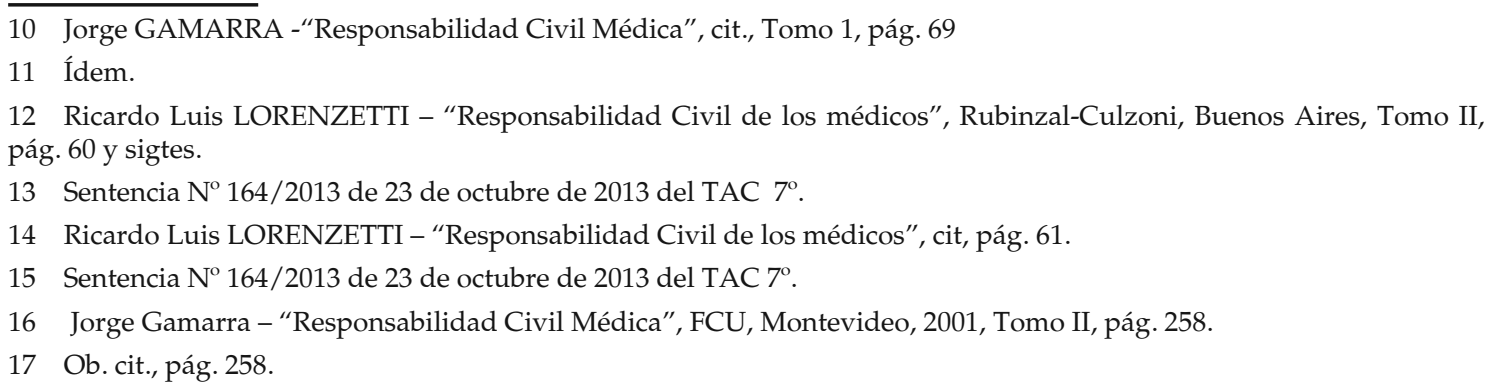




\subsection{El daño}

En cuanto al daño, el mismo debe ser probado y debe tratarse de un daño producido a raíz del actuar culposo del médico, que de haber actuado conforme al estándar de conducta medio, no se hubiese producido.

En definitiva, para que se configure responsabilidad civil médica es necesario que el galeno con su actuar negligente, imperito o imprudente (culpa médica) genere un daño a un tercero que no se habría producido de haberse obrado con el estándar medio de diligencia.

\section{LA EMERGENCIA SANITARIA}

En nuestro país, la Constitución mandata especialmente al Estado a legislar en materia de salud e higiene públicas ${ }^{18}$. Concretamente, en su artículo 44 establece que: "El Estado legislará en todas las cuestiones relacionadas con la salud e higiene públicas".

En cumplimiento de dicha disposición constitucional, el Parlamento dictó La Orgánica de Salud Pública No 9.202, por la cual se le atribuye al Ministerio de Salud Pública la siguiente competencia en materia de higiene pública $\left(\operatorname{art.} 2^{\circ}\right.$ ):

a) la adopción de todas las medidas que estime necesarias para mantener la salud colectiva y su ejecución por el personal a sus órdenes, dictando todos los reglamentos y disposiciones necesarios para este fin primordial;

b) en caso de epidemia o de serias amenazas de invasión de enfermedades infecto contagiosas, la inmediata adopción de medidas conducentes a mantener indemne al país o disminuir los estragos de la infección;

c) determinar el aislamiento y detención de las personas que, por sus condiciones de salud, pudieran constituir un peligro colectivo;

d) establecer las condiciones higiénicas que deben observarse en establecimientos públicos y privados;

e) difundir el uso de las vacunas y sueros preventivos como agentes de inmunización, imponer su uso en casos necesarios y vigilar el cumplimiento de las leyes que imponen la obligatoriedad de vacunación y revacunación antivariólica;

f) reglamentar y contralorear el ejercicio de la medicina, la farmacia y las profesiones derivadas;

g) ejercer la policía higiénica de los alimentos; y

h) propender por todos los medios a la educación sanitaria del pueblo.

Quiere decir, que al amparo de dicha ley, el Estado uruguayo cuenta con un marco normativo habilitante para poder disponer a modo de ejemplo, una cuarentena obligatoria o el aislamiento con fines preventivos de determinado sector de la población.

18 Ver: Carlos E. DELPIAZZO - “Derecho Administrativo Especial” cit., volumen 1, tercera edición actualizada y ampliada, pág. 450 y sigtes. 
Asimismo, la propia Ley establece que en caso de epidemia o de serias amenazas de invasión de enfermedades infecto-contagiosas, el Poder Ejecutivo dispondrá la intervención de la fuerza pública, para garantir el fiel cumplimiento de las medidas dictadas (art. 2 lit. b. inc. 2). Con lo cual, la Ley Nº 9.202 también ofrecía soluciones para el caso de necesidad de uso de la fuerza pública.

En este contexto normativo y ante la llegada del COVID -19 al Uruguay, el Poder Ejecutivo dictó el Decreto No 93/020 de 13 de marzo de 2020 por el cual dispuso “Declárase el estado de emergencia nacional sanitaria como consecuencia de la pandemia originada por el virus COVID-19" (art. $\left.1^{\circ}\right)$.

Entre las medidas adoptadas por dicho Decreto, no se dispuso el confinamiento o cuarentena general obligatoria, sino que se optó por un sistema de exhortación a la población a quedarse en sus hogares en la medida de que ello fuera posible ${ }^{19}$.

En definitiva, al momento de la llegada del COVID 19 a nuestro territorio, el Uruguay contaba, a través de la Ley $\mathrm{N}^{\circ} 9.202$, con un marco normativo suficiente como para poder disponer de una cuarentena general obligatoria, el asilamiento de personas, el uso de la fuerza pública para el cumplimiento de medidas sanitarias y la declaración de emergencia sanitaria. En este contexto, el Estado uruguayo optó por una exhortación a la población de quedarse en sus casas en la medida que fuera posible, decretando sí la Emergencia Sanitaria mediante el Decreto No 93/020.

\section{SITUACIONES ASISTENCIALES ESPECIALES DURANTE LA EMERGENCIA SANITARIA}

El avance del COVID- 19 en todo el mundo y la estrategia de prevención del mismo, determinó en el plano de los hechos, la existencia de situaciones asistenciales especiales tales como ser la carencia de recursos materiales, la necesidad de migrar las consultas en policlínica a la consulta telefónica, la obligación de subrogar especialidades diferentes a aquellas para las cuales se cuenta con título habilitante y la necesidad de conjugar el derecho del paciente a estar acompañado con la imposibilidad de disponer de equipos de protección e infraestructura para los acompañantes.

Todas dichas situaciones especiales, nos obligan a repensar la responsabilidad médica tradicional a la luz de situaciones absolutamente excepcionales.

\subsection{Insuficiencia de recursos materiales}

Tal vez el fenómeno asistencial más excepcional que ha desencadenado la Pandemia por COVID- 19 ha sido la carencia de recursos materiales (respiradores artificiales, equipos de protección personal, camas de cuidados intensivos, hisopos, test reactivos, etc.).

En efecto, la velocidad de contagio de la enfermedad y la afección pulmonar grave que provoca en los casos más graves, determina que una importante cantidad de personas al mismo tiempo requieran de internación en cuidados moderados o intensivos con

19 Carlos E. DELPIAZZO - "El Derecho Administrativo en Tiempos de Emergencia”, Ecuador, 2020 trabajo inédito de próxima aparición en Jaime VILLACRECSES (Coordinador) - "Derecho Administrativo en época de emergencia" (C.E.P., Quito, 2020). 
lo cual, se produce un colapso del sistema sanitario. Esto es, los recursos materiales y humanos dispuestos para la atención de los pacientes, no son suficientes.

En ese escenario de escases de recursos, el galeno debe resolver temas de suma relevancia práctica y de dimensión ética y humana como ¿a quién debe priorizarse?, ¿por qué? Y sobre todo ¿en base a qué criterios?

$\mathrm{Al}$ respecto, se ha señalado con acierto que resulta preocupante: "el surgimiento de guías para la distribución de recursos escasos, como ingresos a CTI, por ejemplo, donde más allá de los criterios habituales de severidad y utilidad del recurso para ese evento en particular, se cuelan criterios de valoración diferente de la vida humana, especialmente según la edad, como es el caso, por ejemplo, de las pautas de la Sociedad Española de Medicina Intensiva, Crítica y Unidades Coronarias, que si bien indican que la edad cronológica "no debería ser el único elemento a considerar en las estrategias de asignación", plantean el criterio de "maximización del número de años salvados", que es justo lo contrario, lo que además plantea el problema de asegurar la supervivencia de los salvados frente a cualquier otra eventualidad de sus vidas, así como los años de vida libres de discapacidad para las personas ancianas. El criterio 23 de estas mismas pautas propone "tomar en consideración el valor social" de la persona para decidir su ingreso a CTI. ¿Quién decide cuál es el valor social de un ser humano? ¿Y por qué es mayor o menor que el de otro?"20.

En efecto, en las Pautas de la Sociedad Española de Medicina Intensiva, Crítica y Unidades Coronarias ${ }^{21}$, se introdujeron criterios para la situación de desborde de las Unidades de Cuidados Intensivos durante la emergencia sanitaria en donde, entre otras cosas, se recomienda tener en cuenta:

a) ante pacientes críticos con otras patologías críticas que no puedan estar en otras áreas asistenciales, como reanimación o semicríticos, diferentes a la infección respiratoria por COVID-19, se debe valorar ingresar prioritariamente a quien más se beneficie o tenga mayor expectativa de vida, en el momento del ingreso (pauta $\mathrm{N}^{\mathrm{o}} 15$ );

b) ante dos pacientes similares, se debe priorizar a la persona con más años de vida ajustados a la calidad (AVAC) o QALY (Quality-Adjusted Life Year). Son un indicador combinado del estado de la salud que aúna cantidad y calidad de vida. Priorizar la mayor esperanza de vida con calidad (pauta $\mathrm{N}^{\mathrm{o}} 16$ );

c) en personas mayores se debe tener en cuenta la supervivencia libre de discapacidad por encima de la supervivencia aislada (pauta $\mathrm{N}^{\mathrm{o}} 17$ );

d) valorar cuidadosamente el beneficio de ingreso de pacientes con una expectativa de vida inferior a 2 años, establecida mediante herramienta NECPAL o similar (pauta $\mathrm{N}^{\mathrm{o}} 21$ );

20 Delia Sánchez - "Ética y salud pública en tiempos de Covid-19" en Revista Médica Uruguaya, Año 2020; Número 36(2), pág. 117-118

21 Sociedad Española de Medicina Intensiva, Crítica y Unidades Coronarias - "Recomendaciones Éticas para la toma de decisiones en la situación excepcional de crisis por Pandemia COVID 19 EN LA unidades de Cuidados Intensivos en https://semicyuc.org/wp-content/uploads/2020/03/\%C3\%89tica_SEMICYUC-COVID-19.pdf 
e) tener en cuenta otros factores como, por ejemplo, personas a cargo del paciente para tomar decisiones maximizando el beneficio del máximo de personas (pauta $\mathrm{N}^{\mathrm{o}} 22$ );

f) tener en cuenta el valor social de la persona enferma (pauta $\mathrm{N}^{\mathrm{o}} 23$ ).

Tal como puede advertirse, en estas situaciones de desborde de los servicios de cuidados intensivos y escasez de recursos materiales, se postularon criterios específicos que el médico debió valorar en cada caso para determinar a modo de ejemplo, a qué ser humano le prestaba asistencia y a cuál, se lo dejaba morir.

En este sentido, adviértase que algunas pautas pueden ser consideradas objetivas, como el estado del paciente o la edad. No obstante, hay criterios que ponen en un verdadero dilema ético al médico en tanto ¿quién puede definir cuál es el "valor social" de un ser humano? Y cabe aún más cuestionarse, ¿corresponde dar prioridad a quién tenga más "valor social"?

Entiendo que la respuesta negativa se impone. No obstante, sin perjuicio de las respuestas que cada uno pueda darle a estas preguntas de carácter bioético que exceden ampliamente el objeto de este trabajo, corresponde analizar el impacto de dichas decisiones en la responsabilidad médica. Esto es, si el médico incurre en responsabilidad penal o civil en caso de que tenga que priorizar a un paciente sobre otro, privando a uno de ellos de asistencia.

$\mathrm{Al}$ respecto, entendemos que la respuesta es que, en esos casos, el médico no incurre en responsabilidad en tanto "Impossibilium nulla obligatio", esto es, nadie está obligado a lo imposible. Si el médico tiene dos pacientes que requieren un respirador y únicamente cuenta con un equipo, entonces escapa a la lógica y a la razón que se le pueda imputar responsabilidad por no haber salvado a ambos. En efecto, podrá caberle un reproche jurídico si la opción es arbitraria o interesada pero no le cabrá responsabilidad alguna por no haber podido salvar ambas vidas cuando no estaban dadas las condiciones materiales para hacerlo.

A más ahondamiento, entendemos que la responsabilidad tampoco podría nacer en tanto en estos casos habría operado una causa de justificación que excluye la ilicitud. En este sentido, si bien las causas de justificación están previstas expresamente para la responsabilidad penal y no para la responsabilidad civil, la doctrina entiende pacíficamente que son de aplicación también en este ámbito 22 .

22 Jorge GAMARRA - “Tratado de Derecho Civil Uruguayo”, F.C.U., Montevideo, 1981, pág. pág. 221 y ss. 
Concretamente, si bien puede resultar discutible ${ }^{23}$, entendemos que podría operar como causal de justificación el estado de necesidad, en tanto se cumplirían los requisitos exigidos para que pueda invocarse: existencia de dos bienes contrapuestos, inmediatez e inevitabilidad; que la situación de necesidad no la haya generado quien la va a invocar; que deba recurrir a un comportamiento que lesiona a un tercero debido a dicha situación de necesidad y que el mal causado deba ser de igual o menor jerarquía que el amenazado.

En primer lugar, existen dos bienes opuestos, en tanto el galeno debe elegir entre brindarle asistencia a una $\mathrm{u}$ a otra persona, siendo claro que el ordenamiento tutela la vida como bien jurídico con independencia de los criterios o pautas que obligan al médico a decidir sobre un caso u otro.

En segundo lugar, la situación es inmediata ya que la opción no puede postergarse so pena de perjudicar a ambos pacientes y en cuanto la atención debe brindarse cuanto antes. Asimismo, también es inevitable ya que ningún sistema de salud del mundo podía prever que se requiriera una cantidad de camas tan importantes de CTI al mismo tiempo.

En tercer lugar, está claro que la situación de necesidad no se generó por el galeno ya que no responde a su actuación profesional sino a un fenómeno absolutamente ajeno a él como es el avance de la Pandemia por COVID 19.

En cuarto lugar, también se configura un comportamiento que lesiona un derecho de un tercero en tanto al no ingresar a un paciente que necesita cuidados intensivos, se lo está privando de su derecho a la salud e incluso, se lo puede estar privando de su derecho a vivir.

En quinto lugar, también se podría decir que el mal causado es de igual o menor jerarquía que el amenazado ya que al aplicarse la pauta para seleccionar a los pacientes se opta por evitar la pérdida de la mayor cantidad de años/calidad de vida por paciente. Esto es, si bien se debe optar por dos bienes jurídicos tutelados de la misma jerarquía (vida) se opta por causar la menor cantidad de daño priorizando a aquel, cuya no asistencia determinaría una mayor cantidad de años perdidos.

Por último, debe señalarse que en caso de que las pautas de triage para la selección de pacientes a ingresar a CTI proviniera de la institución de asistencia o de la propia autoridad sanitaria, también podría invocarse que ha operado como causa de justificación respecto del médico, la obediencia debida (art. 29 del Código Penal) en tanto estaría cumpliendo con la orden de una autoridad con competencia para darla.

23 En función de lo establecido por el inciso $2^{\circ}$ del art, 27 del Código Penal, y entendiendo que los requisitos de la causa de justificación a nivel penal se trasladan íntegramente a su aplicación civil, alguien podría llegar a señalar que el estado de necesidad no puede ser aplicado a quien intenta prevenir un daño que le ocurre a un tercero, en tanto el tercero no es un pariente consanguíneo de la línea recta o colateral hasta el segundo grado inclusive, ni el cónyuge, ni los padres o hijos naturales reconocidos o adoptivos. Frente a esta crítica, alguien podría señalar que el paciente no es cualquier tercero para el médico, sino uno respecto del cual, tiene la obligación de brindar asistencia por lo que trasladando la causal al ámbito civil ello permitiría excluir la ilicitud, 
En definitiva, entendemos que, si a causa de la escasez de recursos materiales, un médico debe optar entre brindarle asistencia a un paciente o a otro en base a pautas objetivas y evitando el mal mayor y con ello causa un daño a otro paciente no priorizado, no incurre en responsabilidad médica de ningún tipo ya que opera en el caso una causa de justificación que excluye la ilicitud y que, en este caso, y dependiendo de las circunstancias, podría ser el estado de necesidad o la obediencia debida.

\subsection{Consulta médica telefónica}

Durante la pandemia, otra situación asistencial especial que se ha planteado es que, a solicitud de varias instituciones de asistencia médica, los médicos se han visto obligados a realizar la consulta en policlínica de forma remota. Esto es, a través de llamados telefónicos, pudiendo únicamente citar en forma presencial al paciente cuando de la consulta telefónica quedara una duda razonable sobre el diagnóstico o tratamiento a seguir.

Como puede advertirse, dicha modalidad de excepción se contrapone con normas elementales que indican que la asistencia y el proceso de diagnóstico son necesariamente presenciales.

En efecto, el art. 24 de la Ley N 19.286 publicada el 17 de octubre de 2014 que aprueba el Código de Ética Médica establece que: “El ejercicio clínico de la medicina requiere el vínculo directo con el paciente. La complementación de la asistencia médica a distancia a través de los medios de comunicación como telemedicina, seguirá los principios de este Código" (destacado nuestro).

En este sentido, se ha definido el diagnóstico como un proceso que cuenta con diferentes etapas y que "comienza con el examen corporal del paciente y su interrogatorio por parte del médico, quien de esta manera busca obtener los primeros y más elementales signos de la enfermedad que deberán complementar, como sucede frecuentemente, los análisis y exámenes clínicos, la historia del paciente y antecedentes..."24.

Es por ello, que la consulta telefónica como mecanismo para diagnosticar e indicar un tratamiento o incluso para repetir medicación ${ }^{25}$, parte de un problema de base que es la ausencia de la primera parte del proceso diagnóstico sin la cual, resulta imposible cumplir con lo dispuesto por la ley.

Por otra parte, tampoco puede confundirse este tipo de prácticas con la telemedicina ya que el factor esencial en este tipo de prestación es la complementariedad. En efecto, el art. 3 lit. F de la Ley de Telemedicina N 19.869 de 15 de abril de 2020, bajo el nomen iuris "Complementariedad" establece que: "El ejercicio clínico de la medicina requiere el vínculo directo con el paciente. La telemedicina es un complemento a la asistencia brindada por el médico tratante (artículo 24 de la Ley $\mathrm{N}^{\mathrm{o}}$ 19.286, de 25 de setiembre de 2014)" (destacado nuestro).

24 Jorge GAMARRA - "Responsabilidad Médica", cit., Tomo I, pág. 68.

25 Ver: Baltasar Aguilar Fleitas - "Historias Clínicas" en Revista Uruguaya de Cardiología, Montevideo, Vol.34, N², Agosto de 2019. 
Sin embargo, la consulta telefónica tal como fue instaurada de ninguna forma puede considerarse un complemento, sino que es verdaderamente sustitutiva de la consulta presencial y en consecuencia, se encuentra reñida con la ley y debe cesar cuanto antes, resultando ilegítimo su mantenimiento.

Asimismo, dicha ilegitimidad no se salva con la posibilidad de citar al paciente si existe una "duda razonable", ya que el surgimiento de la duda estará también condicionado por la ausencia de examen físico. Esto es, las dudas que tal vez se habrían generado con un examen físico pueden no generarse sin el examen presencial.

Sin perjuicio de ello, en caso de incurrirse en un error o demora de diagnóstico, que se podría haber evitado de haberse podido realizar el examen presencial, entiendo que el médico no sería responsable ya que esta modalidad de atención le fue impuesta por el centro asistencial debiendo el médico acatarla para poder seguir prestando atención.

Con independencia de ello, ante este tipo de modalidades de atención entendemos que resulta imprescindible recabar el consentimiento informado del paciente para acceder a esta modalidad de consulta, y además, consignar debidamente el la Historia Clínica que a raíz de la Pandemia y por pedido del Centro asistencial, se está atendiendo bajo esta modalidad telefónica.

En definitiva, la consulta telefónica omite el vínculo presencial que necesariamente debe existir para realizar un diagnóstico o para indicar un tratamiento y no reviste el carácter complementario propio de la telemedicina, sino que es verdaderamente sustitutiva de la consulta presencial. Dicho extremo no se salva por la posibilidad de citar al paciente en caso de duda razonable ya que todo el procedimiento del cual podría surgir la duda, se encuentra viciado por la falta de vínculo directo con el paciente. Sin perjuicio de ello, en caso de producirse una mala praxis producto de esta modalidad de atención, la responsabilidad no será atribuible al médico a quien se le impusieron estas condiciones laborales.

\subsection{Necesidad de subrogación de otras especialidades}

Sumado a la escasez de recursos materiales, la Pandemia también ha demostrado que en los picos de contagio se presenta escasez de trabajadores médicos capacitados para ejercer la medicina intensiva. Asimismo, el contagio del propio personal sanitario, lleva a que rápidamente mermen los recursos humanos que están en condiciones sanitarias de seguir prestando asistencia médica.

Es por ello, que en varios países del mundo fue necesario que médicos de otras especialidades, ajenas a las de los cuidados intensivos, asuman asistencia en este tipo de unidades y hagan las veces de médicos intensivistas aun, cuando no contaran con la especialidad para ello.

Dicho escenario, plantea la problemática de si es posible en nuestro país, ejercer una especialidad médica sin el título habilitante registrado para ello o si por el contrario, se incurre en algún tipo de responsabilidad médica por hacerlo. 
$\mathrm{Al}$ respecto, la regla general es que el título de doctor en medicina habilita el ejercicio en general de las diferentes especialidades, salvo aquellas que expresamente excluye la ley. En efecto, la Ley N 9.202 establece en su art. 13 que: "Nadie podrá ejercer la profesión de médico cirujano, farmacéutico, odontólogo y obstétrico, sin inscribir previamente el título que lo habilite para ello, en las oficinas del Ministerio de Salud Pública".

Por su parte, el Decreto No 346/972 de 16 de mayo de 1927 dispone que "Para ser considerado especialista en cualquier disciplina médica, será imprescindible la inscripción en el Ministerio de Salud Pública del título o certificado correspondiente expedido o revalidado por la Universidad de la República". Asimismo, agrega que "El título será obligatorio para desempeñar cualquier cargo -en la orientación que correspondaen la actividad oficial, mutual o privada (...)".

Por su parte, el art. 18 de la Ley $\mathrm{N}^{\mathrm{o}} 18.335$ de 26 de agosto de 2008 en su lit. c, establece que todo paciente tiene derecho a: "Conocer quién o quiénes intervienen en el proceso de asistencia de su enfermedad, con especificación de nombre, cargo y función".

Por último, conforme al art. 26 del Decreto N 399/088 se dispuso que: “Se exigirá el título de Médico Intensivista homologado por el Ministerio de Salud Pública, para ocupar cargos Médicos en todos los niveles de Escalafón de cada Unidad de Medicina Intensiva".

En consecuencia, cuando el médico debe desempeñarse en una especialidad que no requiere de título habilitante para su ejercicio, no se plantea problema de ningún tipo y podrá hacerlo sin perjuicio de que deberá informar al paciente de su nivel de formación, tal como lo indica el art. 18 de la Ley $\mathrm{N}^{\mathrm{o}} 18.335$.

Sin embargo, el problema se plantearía en el caso de que fuese necesario subrogar especialidades para cuyo caso se requiere de título habilitante (cirujano, farmacéutico, odontólogo, obstétrico e intensivista). En esos casos, corresponde preguntarse si el médico puede asumir en caso de emergencia dichas actividades o si por el contrario, debe abstenerse de hacerlo. Asimismo, en caso de que se entienda que debe hacerlo, también debemos cuestionarnos acerca de cuál es el estándar de diligencia que podría requerírsele al médico en el ejercicio de esa especialidad para la cual no tiene título.

Respecto de la primera pregunta, entendemos que en caso de suscitarse un colapso de los servicios sanitarios y una escasez de recursos humanos que ponga en peligro la asistencia a la población, el médico que es llamado a brindar asistencia, sea cual sea su especialidad, no puede negarse a hacerlo invocando que carece de título habilitante para ello y por el contrario, tiene el deber de asistir en lo que esté a su alcance al paciente en situación de riesgo de vida so pena de correr peligro de incurrir, según las circunstancias, en lo dispuesto por el art. 332 del Código Penal (omisión de asistencia).

Respecto de la segunda pregunta, resulta claro que el estándar de diligencia que se le puede exigir a ese médico no es el de la especialidad que no tiene, sino que dicho estándar debe ser medido conforme a su nivel de formación en ese momento dado $^{26} \mathrm{y}$ conforme a las circunstancias asistenciales en las que le tocó brindar asistencia.

26 Natalia VELOSO GIRIBALDI - "Estatuto de Residentes e Internos" en Carlos E. DELPIAZZO (Coordinador) - "Régimen de Asistencia a la Salud”, F.C.U., Montevideo, 2018, Segunda Edición ampliada y actualizada, pág. 258. 
Sin perjuicio de lo anterior, y en caso de que la emergencia sanitaria hiciera necesaria la subrogación de especialidades, sería conveniente que el Ministerio de Salud Pública emitiera una Resolución estableciendo el orden de prelación en la subrogación de las distintas especialidades, así como la autorización genérica para desempeñar por razones de emergencia, incluso aquellas especialidades para las cuales el ordenamiento exige título habilitante.

En definitiva, en caso de suscitarse un colapso de los servicios sanitarios el médico que es llamado a brindar asistencia, sea cual sea su especialidad, no puede negarse a hacerlo invocando que carece de título habilitante para ello y en ese caso, el estándar de diligencia que se le exigirá no podrá ser el de la especialidad que no tiene, sino el correspondiente a su nivel de formación para la atención de los casos concretos que le haya tocado atender.

\subsection{Vulneración del Derecho a estar acompañado}

Otra situación asistencia atípica que se ha planteado durante la Pandemia, incluso en nuestro país, es la imposibilidad para los pacientes internados por COVID 19 de estar acompañado durante el período de hospitalización. Dicha situación obedece a las más diversas razones logísticas y epidemiológicas, pero, sobre todo, a la incapacidad de poder brindar a cada uno de los acompañantes un equipo completo para protegerse del contagio. Esto ha llevado a situaciones humanamente dramáticas que han impedido a los familiares despedirse de sus seres queridos y en algunos casos, han determinado la muerte en soledad de los pacientes.

Desde el punto de vista jurídico, cabe cuestionarnos como se compatibiliza dicha situación asistencial con el derecho a estar acompañado que, en varias disposiciones, consagra nuestro ordenamiento.

En efecto, el artículo 17 lit. c de la Ley $\mathrm{N}^{\mathrm{o}} 18.335$ establece que todo paciente tiene derecho a: "Estar acompañado por sus seres queridos o representantes de su confesión en todo momento de peligro o proximidad de la muerte, en la medida que esta presencia no interfiera con los derechos de otros pacientes internados y de procedimientos médicos imprescindibles". Por su parte, el art. 26 lit. b) del Código de Ética establece que el médico tiene el deber de: "Facilitar que el paciente logre el diálogo a solas con sus seres queridos".

Sin embargo, si ahondamos en las competencias extraordinarias que la Ley $\mathrm{N}^{\circ} 9.202$ le otorga en su art. 2 num. 3 al MSP, advertimos que compete a la autoridad sanitaria: "Determinar, cuando fuere necesario, por intermedio de sus oficinas técnicas, el aislamiento y detención de las personas que por sus condiciones de salud pudieran constituir un peligro colectivo".

En función de ello, resulta evidente que hay dos situaciones jurídicamente protegidas en contraposición. Por un lado, el derecho del paciente a estar acompañado y por otro, las facultades epidemiológicas para disponer el aislamiento de un paciente en caso de epidemia. 
En definitiva, del ejercicio de las facultades exorbitantes conferidas a la autoridad sanitaria en materia de higiene pública ${ }^{27}$, pueden resultar limitados algunos derechos fundamentales por razones de interés general. En este sentido, entendemos que a pesar de que el aislamiento limita derechos fundamentales de los pacientes, la Ley $\mathrm{N}^{\mathrm{o}} 9.202$ otorga habilitación legal para hacerlo en casos de epidemia donde la falta de aislamiento de un individuo pueda repercutir en la salud colectiva.

\section{CONCLUSIONES}

En función de los desarrollos procedentes podemos arribar a las siguientes conclusiones:

a) la responsabilidad médica es mucho más amplia que la responsabilidad médica civil ya que puede configurarse tanto en el ámbito penal, como en el ámbito civil, administrativo o ético, siendo distintas las consecuencias jurídicas que se imputan dependiendo del ámbito de actuación;

b) para que se configure responsabilidad civil médica es necesario que el galeno con su actuar negligente, imperito o imprudente (culpa médica) genere un daño a un tercero que no se habría producido de haberse obrado con el estándar medio de diligencia;

c) al momento de la llegada del COVID 19 a nuestro territorio, el Uruguay contaba, a través de la Ley $\mathrm{N}^{\circ}$ 9.202, con un marco normativo suficiente como para poder disponer de una cuarentena general obligatoria, el aislamiento de personas, el uso de la fuerza pública para el cumplimiento de medidas sanitarias y la declaración de emergencia sanitaria. En este contexto, el Estado uruguayo optó por una exhortación a la población de quedarse en sus casas en la medida que fuera posible, decretando sí la Emergencia Sanitaria mediante el Decreto No 93/020;

d) la existencia de situaciones asistenciales especiales provocadas por la expansión del COVID 19 tales como ser la carencia de recursos materiales, la necesidad de migrar las consultas en policlínica a la consulta telefónica, la necesidad de subrogar especialidades diferentes a aquellas para las cuales se cuenta con título habilitante y la limitación del derecho del paciente a estar acompañado, nos obligan a repensar la responsabilidad médica tradicional a la luz de situaciones absolutamente excepcionales;

e) si a causa de la escasez de recursos materiales un médico debe optar entre brindarle asistencia a un paciente y no a otro en base a pautas objetivas y evitando el mal mayor y con ello causa un daño a otro paciente no priorizado, no incurre en responsabilidad médica de ningún tipo ya que opera en el caso una causa de justificación que excluye la ilicitud y que, en este caso, y dependiendo de las circunstancias, podría ser el estado de necesidad o la obediencia debida;

27 Carlos E. DELPIAZZO - “Derecho Administrativo Especial” A.M.F., Montevideo, 2015, Volumen I, Tercera Edición, pág. 443 
f) la consulta telefónica omite el vínculo presencial que necesariamente debe existir para realizar un diagnóstico o para indicar un tratamiento y no reviste el carácter complementario propio de la telemedicina, sino que es verdaderamente sustitutiva de la consulta presencial. Dicho extremo no se salva por la posibilidad de citar al paciente en caso de duda razonable ya que todo el procedimiento del cual podría surgir la duda, se encuentra viciado por la falta de vínculo directo con el paciente. Sin perjuicio de ello, en caso de producirse una mala praxis producto de esta modalidad de atención, la responsabilidad no será atribuible al médico a quien se le impusieron estas condiciones laborales;

g) en caso de suscitarse un colapso de los servicios sanitarios el médico que es llamado a brindar asistencia, sea cual sea su especialidad, no puede negarse a hacerlo invocando que carece de título habilitante para ello y en ese caso, el estándar de diligencia que se le exigirá no podrá ser el de la especialidad que no tiene, sino el correspondiente a su nivel de formación para la atención de los casos concretos que le haya tocado asistir; y

h) las potestades en materia de higiene pública conferidas a la autoridad sanitaria por la Ley $N^{\circ} 9.202$ habilitan a limitar el derecho del paciente a estar acompañado por razones de interés general como puede ser la contención de la propagación del virus o la imposibilidad de disponer de equipos de protección personal para todos los acompañantes.

\section{BIBLIOGRAFÌA}

ACHÁVAL, Alfredo - "Responsabilidad Civil del Médico", Buenos Aires, 1992, Abeledo Perrot, Segunda Edición Ampliada y Actualizada, pág. 129 y ss.

Aguilar Fleitas, Baltasar - "Historias Clínicas” en Revista Uruguaya de Cardiología, Montevideo, Vol.34, No2, Agosto de 2019.

BRITO, Mariano R. - "Régimen disciplinario. Principios fundamentales del procedimiento, infracción y sanción disciplinarios", en Procedimiento administrativo, Acali, Montevideo, 1977, pág. 138.

DELPIAZZO, Carlos E. - "El Derecho Administrativo en Tiempos de Emergencia", Ecuador, 2020 en Jaime VILLACRECSES (Coordinador) - "Derecho Administrativo en época de emergencia" (C.E.P., Quito, 2020).

DELPIAZZO, Carlos E. - "Derecho Administrativo Especial" A.M.F., Montevideo, 2015, Volumen I, Tercera Edición, pág. 443

DURAN MARTINEZ, Augusto - "Principios del procedimiento disciplinario", en Procedimiento administrativo, UCUDAL, Montevideo, 1991, pág. 82.

FERNÁNDEZ, Gonzalo - "El ejercicio ilegal de la medicina: Las hipótesis de responsabilidad penal", en "III Jornadas de Responsabilidad Médica" (1998)", S.M.U., pág. 54. 
GAMARRA, Jorge - ““Tratado de Derecho Civil Uruguayo”, F.C.U., Montevideo, 1991, Tomo XIX, pág. 221 y ss.

GAMARRA, Jorge - "Responsabilidad Civil Médica”, FCU, Montevideo, 1999, Tomo I, págs. 16.

LORENZETTI, Ricardo Luis - "Responsabilidad Civil de los médicos", Rubinzal-Culzoni, Buenos Aires, Tomo II, pág. 60 y sigtes.

LORENZO, Susana - “Sanciones administrativas”, BDF, Montevideo, 1996, pág. 142.

RAVINOVICH, Ricardo - "Responsabilidad del Médico", Astrea, Buenos Aires, 1999, p.107 y 108.

Sánchez, Delia - "Ética y salud pública en tiempos de Covid-19" en Revista Médica Uruguaya, Año 2020; Número 36(2), pág. 117-118

Sociedad Española de Medicina Intensiva, Crítica y Unidades Coronarias - "Recomendaciones Éticas para la toma de decisiones en la situación excepcional de crisis por Pandemia COVID 19 EN LA unidades de Cuidados Intensivos en https://semicyuc. org/wp-content/uploads/2020/03/\%C3\%89tica_SEMICYUC-COVID-19.pdf

Szafir, dora y Venturini, Beatriz - "Responsabilidad médica en el MERCOSUR. Jurisprudencia sistematizada y anotada. Cuadernos del ADCU, tomo II, págs. 387 a 394.

TOMA, Miguel A- “Comisión de Salud Pública. Ley 9.202". Revista de la Oficina Nacional del Servicio Civil. Año I-2006. Nº 30. Pág. 156.

VELOSO GIRIBALDI, Natalia - "Estatuto de Residentes e Internos" en Carlos E. DELPIAZZO (Coordinador) - "Régimen de Asistencia a la Salud", F.C.U., Montevideo, 2018, Segunda Edición ampliada y actualizada, pág. 258. 